\title{
A Rare Localization of Tuberculosis: A Case Report and a Review of the Literature
}

\author{
Faisal El Mouhafid*, Abderrahman Elhjouji, Mohammed Fahssi, Mbarek Yaka, \\ Noueddine Njoumi, Mohammed Tarchouli, Hicham Iraki, Mountassir Moujahid, \\ Abdelmounim Aitali, Aziz Zentar \\ Department of Visceral Surgery, Mohammed V Military Teaching Hospital, Ryad, Rabat, Morocco \\ Email: ^faisalmohafid@gmail.com
}

How to cite this paper: El Mouhafid, F. Elhjouji, A., Fahssi, M., Yaka, M., Njoumi, N., Tarchouli, M., Iraki, H., Moujahid, M., Aitali, A. and Zentar, A. (2021) A Rare Localization of Tuberculosis: A Case Report and a Review of the Literature. Surgical Science, $12,95-101$.

https://doi.org/10.4236/ss.2021.123011

Received: August 15, 2019

Accepted: March 28, 2021

Published: March 31, 2021

Copyright $\odot 2021$ by author(s) and Scientific Research Publishing Inc. This work is licensed under the Creative Commons Attribution International License (CC BY 4.0).

http://creativecommons.org/licenses/by/4.0/

\begin{abstract}
The hepatic tuberculosis is rare. The interest of this Knowledge consists in the diagnostic problems particularly in its primitive and macronodular forms. It touches all ages with a peak of frequency during 17 - 50 years old, and a female prevalence. The clinical picture is polymorphous but it is still dominated by the prolonged fever and the alteration of the general state. Case report: 30-year-old female was admitted to our hospital with painless swelling on the right side of chest and feeling of pressure in the right upper quadrant of abdomen. She has no history of fever, weight loss, and night sweating or poor appetite. On clinical examination, the patient was in good general condition. The inflammatory tumefaction of the right chest wall was marked. The palpation of the abdomen revealed a sensitive hepatomegaly. A CT scan revealed a large cystic liver. The laboratory investigations were normal. This appearance was suggestive of a hydatid cyst of the right liver and a surgical management was decided. But the histological study revealed granulomatous inflammation consisting of tuberculoid type granuloma with caseous necrosis. However, abscess of the liver due to MT was highly suspected and anti-tuberculosis therapy was started, the patient responded well. Conclusion: The analysis of this observation and the data of the literature make it possible to retain the rarity; the polymorph expression and not very suggestive of this location.
\end{abstract}

\section{Keywords}

Liver Abscess, Mycobacterium Tuberculosis, Antibacillary

\section{Introduction}

Hepatic tuberculosis is rare and constitutes less than $1 \%$ of all tuberculosis sites. 
It can take different aspects. It currently benefits from the contribution of diagnostic techniques of molecular biology that allow a diagnosis fast on liver biopsy slides. The positive diagnosis is confirmed by the detection of Koch's bacillus on direct examination, culture and amplification by PCR techniques of granulomas associated with caseous necrosis in the biopsy fragments.

Treatment of primary hepatic tuberculosis is 6 months including 2 months of triple therapy and 4 months of dual therapy [1].

\section{Case Report}

A 30 years old female was admitted to our hospital; without medical or surgical history or associated defects, she had an average socio-economic level. She had no history of tuberculosis or contact with a patient with tuberculosis. The beginning of the history of his illness dates back to 01 months before his hospitalization by the appearance of parietal swelling basi-thoracic right; associated with gravitational pain in the right hypochondrium. Without digestive or respiratory symptoms (no cough, hemoptysis) nor night sweats, all evolving in a context of apyrexia and conservation of the general state.

The clinical examination found a patient in good general condition, apyretic, normotensive, with normal colored conjunctives.

The inspection objectified a swelling next to the 10th and 12th right ribs. Palpation revealed a sensitive hepatomegaly. The ganglionic areas were free. The rest of the somatic examination was peculiar.

The biological assessment was normal. The serological test was negative.

The chest x-ray did not show any obvious lesion. Abdominal computed tomography (Figure 1) showed a cystic lesion of the liver coming into contact with the right lateral thoracic wall,

The decision of a surgical procedure was made: the radiological aspect which was in favor of a hydatid cyst of the liver. A subcostal costal was performed with firstly protection of the operative field by fields soaked with a scolicide solution. Then the puncture of the cyst and aspiration of about 2 liters of purulent fluid, then injection of oxygenated water with cleaning and total aspiration of the liquid, then we performed a resection in dome protruding from the cyst with drainage of the residual cavity after careful inspection of the cavity for any biliary leaks. The liquid is sent for bacteriological examination and histological study of the cystic wall. The bacteriological examination was negative. Histological study of the cyst wall revealed tuberculoid granulomatous inflammations with caseous necrosis.

So the diagnosis of hepatic tuberculosis was retained and anti-bacillary treatment was started for 9 months.

The patient has evolved favorably under medical treatment and Control ultrasound showed complete resolution of liver abscess and swelling (Figure 2).

Clinical, biological and radiological control for one year after the end of treatement and disappearance of the radiological images was normal. 

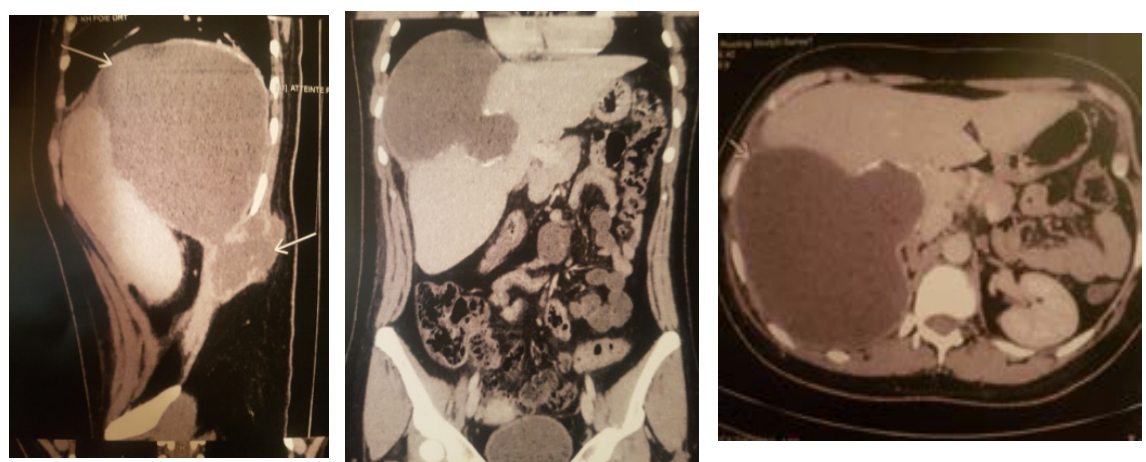

Figure 1. A computed tomography scan (CT) revealed a large cystic liver lesion interesting the right liver extending to involve right lateral chest wall forming a collection in an intermuscular.

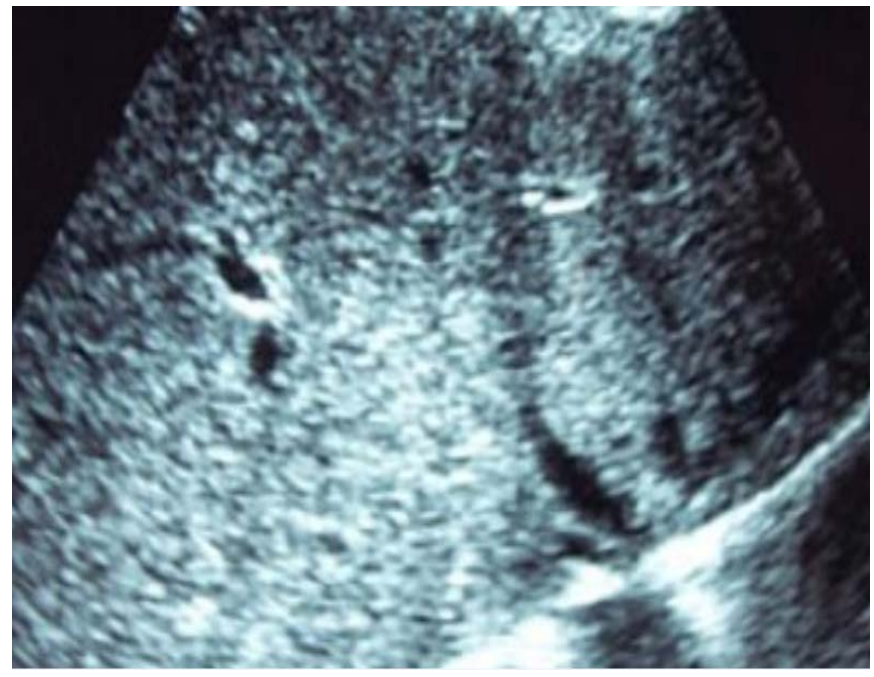

Figure 2. Ultrasound showed complete resolution of liver abscess.

\section{Discussion}

The average age of patients with hepatic tuberculosis was 30 years with extremes ranging from 17 - 50 years [2]. No difference in frequency in both sexes [3] [4] [5], although in a series of cases (14 cases of hepatic tuberculosis collected in the gastroenterology department of Ibn Rochd Hospital, Casablanca between January 1990 and January 2001) they noted a clear female predominance with 12 women for 2 men, a sex ratio of 0.16 [6]. There is a higher incidence of hepatic tuberculosis in the black race [3] [4] [5].

A digestive localization is present in $5 \%$ to $30 \%$ of the cases of tuberculosis occurring in the subjects infected with the HIV [7]. These are hepatic forms in more than $50 \%$ of cases compared to $15 \%$ in the uninfected population. Digestive localizations are very rare when the number of lymphocytes is greater than $250 / \mathrm{mm}^{3}$. However, when this rate is less than $100 / \mathrm{mm}^{3}$, liver damage is more common in the form of a miliary.

Localized involvement is extremely rare in HIV-infected individuals: 9 cases of hepatic abscess have been reported in the literature [8]. 
Unlike secondary involvement, primary hepatic tuberculosis is rare. Its frequency with regard to tuberculosis digestive sites is $0.5 \%$ and $1.2 \%$ [9] [10].

The clinical approach to hepatic tuberculosis is always very delicate because hepatic tuberculosis is considered a clinically silent disease or in symptomatic forms the picture is non-specific or even misleading [11].

TLA is usually confused with hepatoma, pyogenic or amoebic liver abscess and is often diagnosed at autopsy or after laprotomy because of its non specific presentation [12].

The fever can take different aspects: moderate or very high; it is frequent but not constant, and persists [2] in the absence of a specific treatment. Fever was reported in $65 \%$ of cases by Alvarez [13], and $66 \%, 90 \%$ and $63 \%$ respectively by Essop, Hersh and Maharaj according to the Alvarez metanalysis. Abdominal pain was the most common reason for consulting; it was reported by Alvarez (45\%) [13], Essop (66\%), Hersh (50\%) and Maharaj (46\%). In our case the pain was found; it was localized at the level of the right hypochondrium. Asthma, anorexia, weight loss and night sweats [14] are signs often found in patients with hepatic tuberculosis, Hepatomegaly can be painful or painless. The pain is awakened by palpation, sometimes even spontaneously, firm [15], Hepatomegaly was present in $96 \%$ of cases in the series of Alvarez [13]: nodular simulating liver cancer in $55 \%$ of cases and closes in $36 \%$.

Portal hypertension and jaundice are rare or even exceptional, the jaundice is often related to compression of the extrahepatic biliary tract [16] (Table 1).

The contribution of biological examinations in the positive diagnosis of hepatic tuberculosis is very limited. Sedimentation velocity is almost constantly accelerated, but variably [17]. C-reactive protein and fibrinogen can also be elevated [18]. Moderate normocytic anemia can be seen. Pancytopenia can be found in the context of hypersplenism or associated medullary involvement. Apart from the elevation of alkaline phosphatase, liver function remains normal. Serum alkaline phosphatase activity is increased to 1.5 to 5 times the upper limit of normal in $50 \%$ to $75 \%$ [19]. Tuberculin reactions are often positive or phlyctenular [2]; but their negativity can in no way constitute an argument against the diagnosis of this affection.

Abdominal ultrasonography scan usually reaveled hypoechoic lesions in most cases of TB liver abscess [20]. However, a hyperechoic lesion was reported in

Table 1. Clinical signs in different studies.

\begin{tabular}{cccccc}
\hline Clinical signs & $\begin{array}{c}\text { Alvar } \\
\mathrm{Zn}=\mathbf{1 3 0}\end{array}$ & $\begin{array}{c}\text { Essop } \\
\mathbf{N}=\mathbf{9 6}\end{array}$ & $\begin{array}{c}\text { Hersh } \\
\mathbf{N}=\mathbf{2 0 0}\end{array}$ & $\begin{array}{c}\text { Maharaj } \\
\mathbf{N}=\mathbf{4 1}\end{array}$ & $\begin{array}{c}\text { Karam } \\
\mathbf{N}=11\end{array}$ \\
\hline Fever (\%) & 65 & 70 & 90 & 63 & 36 \\
Abdominal pain (\%) & 45 & 66 & 50 & 46 & 56 \\
Weight loss (\%) & 55 & - & 75 & 61 & 100 \\
Hepatomegaly (\%) & 96 & 80 & 95 & 95 & 81 \\
Jaundice (\%) & 35 & 11 & 15 & 14 & 9 \\
\hline
\end{tabular}


one case [21]. CT scan usually demonstrates a low-attenuation lesion with or without ring enhancement [22].

Thus, the specificity of ultrasonography and CT is low in detecting TLA but in defining the site, size and the nature of the abscess, their value is indispensable [12].

It is difficult to make the diagnosis of hepatic tuberculosis clinical, biological and radiological data, hence the need for histological confirmation, although in a number of cases, histological lesions may be found in other pathologies that raise the problem of the etiological diagnosis of hepatic granulomatosis.

The hepatic fragment can be obtained either by a biopsy puncture Transvarietal liver, either by laparoscopic biopsy or during exploratory laparotomy.

The detection of tubercle bacilli by culture is positive in only $10 \%$ and $35 \%$ of cases [23].

Molecular biology techniques by DNA amplification of BK are not part of routine examinations. They allow to obtain in 48 hours the diagnosis [24] [25]. Recently, Alcantra et al. [24] have developed the use of PCR for the identification of BK in the biopsy fragment. He reported $100 \%$ success in cases where there is caseous necrosis against $78 \%$ in front of a granuloma or other suspicious lesion of tuberculosis.

Caseous necrosis test is positive in $67 \%$ of cases for Alvarez et al., in $83 \%$ for Essop et al., in 51\% for Maharaj et al. [26] [27]. Even caseous necrosis does not represent tuberculosis exclusively [28], the treatment outcome of anti-tuberculous regimen confirms the diagnosis indirectly. The lack of a positive tuberculosiss culture and PCR results did not influence the final diagnosis, especially in a country with high burden of tuberculosis [29].

Management of TLA includes anti tubercular therapy for one year alone or in combination with percutaneous drainage [21]. Surgical management is usually reserved for cases of multiple unsuccessful attempts of percutaneous aspiration, inaccessible site, and multiseptate nature of the abscess [30].

\section{Conclusion}

Hepatic tuberculosis represents $-1 \%$ of all cases of tuberculosis. Most of these cases are immunocompromised individuals infected with HIV. It is most often a form secondary to another tuberculous focus, more rarely a primitive form. This location raises a number of difficult diagnostic problems because of its clinical expression; biological; radiological, and histological polymorphous and evocative, hence the importance of always thinking about this diagnosis in front of any granulomatous or pseudo-tumoral liver disease especially in a country of endemic tuberculosis and on an immunocompromised field.

\section{Conflicts of Interest}

The authors declare no conflicts of interest regarding the publication of this paper. 


\section{References}

[1] Tostmann, A., Boeree, M.J., Aarnoutse, R.E., de Lange, W.C., van der Ven, A.J. and Dekhuijzen, R. (2008) Antituberculosis Drug-Induced Hepatotoxicity: Concise Upto-Date Review. Journal of Gastroenterology and Hepatology, 23, 192-202. https://doi.org/10.1111/j.1440-1746.2007.05207.x

[2] Nassar, I., Errabih, I., Krami, I., Hammani, L., Ouazzani, H. and Imani, F. (2008) DIG-WS-36 Tuberculose hépatique priitive: À propos de 10 cas. Journal de Radiologie, 88, 1538. https://doi.org/10.1016/S0221-0363(07)81728-8

[3] Bernard, E., et al. (1985) Tuberculose hépatique à forme pseudo-tumorale. A propos d'une observation. Ann Med Interne (Paris), 21, 135-136. PMID: 4096565.

[4] Hickey, N., McNulty, J.G., Osborne, H. and Finucane, J. (1999) Acute Hepatobiliary Tuberculosis: A Report of Two Cases and a Review of the Literature. European Radiology, 9, 886-889. https://doi.org/10.1007/s003300050761

[5] Rogé, F., Berthet, B., Nikolajevic, Z. and Assadourian, R. (2000) Vomumineuse adénopathie tuberculeuse du pédicule hépatique. Annales de Chirurgie, 125, 292 295. https://doi.org/10.1016/S0001-4001(00)00138-0

[6] AITKHOUYA.S. (2002) LA T.H (à propos de 14 cas) Thesis Medicine No. 29. Casablanca.

[7] Aubry, P. (1994) Apport de l'échographie des organes pleins de l'abdomen au stade 4, de l'infection par le virus de l'immuno déficience humaine. 43-52.

[8] Muinelo, F.M. (1999) Absceso hepatico tuberculoso en VIH.

[9] Kennethy, Y. (1999) Isolated Hepatic Tuberculosis: Report of Five Cases and Review of the Literature.

[10] AkÇay, M.N., Polat, K.Y., Ören, D. and Öztürk, G. (2004) Primary Tuberculous Liver Abscess. A Case Report and Review of Literature. International Journal of Clinical Practice, 58, 625-627. https://doi.org/10.1111/j.1368-5031.2004.00105.x

[11] Mert, A., Ozarzs, R., Tabak, F., Ozturk, R. and Bilir, M. (2003) Localized Hepatic Tuberculosis. European Journal of Internal Medicine, 14, 511-512. https://doi.org/10.1016/j.ejim.2003.09.007

[12] Hassani, K.I., Ousadden, A., Ankouz, A., Mazaz, K. and Taleb, K.A. (2010) Isolated Liver Tuberculosis Abscess in a Patient without Immunodeficiency: A Case Report. World Journal of Hepatology, 2, 354-357. https://doi.org/10.4254/wjh.v2.i9.354

[13] Johansen, I.S., Thomen, V.O., Johansen, A., Andersen, P. and Lundgren, B. (2002) Evaluation of a New Commercial Assay for Diagnosis of Pulmonary and Nonpulmonary Tuberculosis. European Journal of Clinical Microbiology and Infectious Diseases, 21, 455-460. https://doi.org/10.1007/s10096-002-0737-x

[14] Diallo, I., Mbengue, A., Gning, S.B., Amar, M.A., Ndiaye, B., Diop, Y., Fall, F. and Baye, P.S. (2016) Hepatosplenic Tuberculosis Simulating Secondary Malignant Lesions with Cholangitis. BMC Research Notes, 9, Article No. 316. https://doi.org/10.1186/s13104-016-2091-6

[15] Ch'ng, L.S., Amzar, H., Ghazali, K.C., et al. (2018) Imaging Appearances of Hepatic Tuberculosis: Experience with 12 Patients. Clinical Radiology, 73, 321.E11-321.E16. https://doi.org/10.1016/j.crad.2017.10.016

[16] Bensabbahia, D., Jouhadi, Z., Labied, S., Najib, J. and Chbani, K. (2015) P-101Tuberculose hépatique à propos de 3 cas. Archives de Pédiatrie, 22, 258. https://doi.org/10.1016/S0929-693X(15)30285-2

[17] Diallo, I., Mbengue, A., Gning, S.B., et al. (2016) Hepatosplenic Tuberculosis Simu- 
lating Secondary Malignant Lesions with Cholangitis. BMC Research Notes, 9, Article No. 316. https://doi.org/10.1186/s13104-016-2091-6

[18] Ai, J.-W., Li, Y., Cheng, Q., et al. (2018) Diagnostic of Local Hepatic Tuberculosis through Next-Generation Sequencing: Smarter, Faster and Better. Clinics and Research in Hepatology and Gastroenterology, 42, 178-181.

https://doi.org/10.1016/j.clinre.2018.04.007

[19] Wong, S.S.M. (2014) Hepatic Tuberculosis: A Rare Cause of Fluorodeoxyglucose Hepatic Superscan with Background Suppression on Positron Emission Tomoqraophy. Singapore Medical Journal, 55, e101-e103.

https://doi.org/10.11622/smedj.2013237

[20] Jain, R., Sawhney, S., Gupta, R.G. and Acharya, S.K. (1999) Sonographic Appearances and Percutaneous Management of Primary Tuberculous Liver Abscess. Journal of Clinical Ultrasound, 27, 159-163.

https://doi.org/10.1002/(SICI)1097-0096(199903/04)27:3<159::AID-JCU11>3.0.CO; $\underline{2-K}$

[21] Chen, H.-C., Chao, Y.-C., Shyu, R.-Y. and Hsieh, T.-Y. (2003) Isolated Tuberculous Liver Abscesses with Multiple Hyperechoic Masses on Ultrasound: A Case Report and Review of the Literature. Liver International, 23, 346-350.

https://doi.org/10.1034/j.1478-3231.2003.00861.x

[22] Yu, R.S., Zhang, S.Z., Wu, J.J., et al. (2004) Imaging Diagnosis of 12 Patients with Hepatic Tuberculosis. World Journal of Gastroenterology, 10, 1639-1642. https://doi.org/10.3748/wjg.v10.i11.1639

[23] Kanagaraj, A., Marthandam, L.R., Sriramakrishnan, V., et al. (2008) Tuberculous Liver Abscess. J Assoc Physicians India, 56, 647-648.

[24] Alcantara-Payawal, D.E., Matsumura, M., Shiratori, Y., et al. (1997) Direct Ditection of Mycobacterium tuberculosis Using Polymerase Chain Reaction Assay among Patient with Hepatic Granuloma. Journal of Hepatology, 27, 620-627. https://doi.org/10.1016/S0168-8278(97)80078-5

[25] Amaris, J. (1997) Aspects radiologiques du tuberculome hépatique. Gastroentérologie Clinique et Biologique, 21, 888-892.

[26] Seve, P. (1998) Tuberculose hépatique: Un cas à forme pseudo-tumorale. Ann Med Interne (Paris), 149, 386-388.

[27] Alvarez, S.Z. (1998) Hepatobiliary Tuberculosis. Journal of Gastroenterology and Hepatology, 13, 833-839. https://doi.org/10.1111/j.1440-1746.1998.tb00743.x

[28] Lee, S.-W., Lien, H.-C. and Chang, C.-S. (2010) Tuberculous Liver Abscess in a Case without Lung Involvement. The Kaohsiung Journal of Medical Sciences, 26, 99-104. https://doi.org/10.1016/S1607-551X(10)70015-2

[29] Bangaroo, A.K. and Malhotra, A.S. (2005) Isolated Hepatic Tuberculosis. Journal of Indian Association of Pediatric Surgeons, 10, 105-107.

https://doi.org/10.4103/0971-9261.16474

[30] Kumar, P., Kakar, A. and Gogia, A. (2015) Tubercular Liver Abscess: A Rare Presentation of a Common Disease. Current Medicine Research and Practice, 5, 232-234. https://doi.org/10.1016/j.cmrp.2015.06.005 